\title{
Foot Loading Pattern Variations between Normal Weight, Overweight, and Obese Adults Aged 24 to 50 Years
}

\author{
Suhad K. R. Al-Magsoosi, Albert K. Chong \\ University of Southern Queensland West Street, Toowoomba QLD, Australia \\ Email: U1052339@umail.usq.edu.au,Chonga@usq.edu.au
}

How to cite this paper: Al-Magsoosi, S.K.R. and Chong, A.K. (2019) Foot Loading Pattern Variations between Normal Weight, Overweight, and Obese Adults Aged 24 to 50 Years. Journal of Biosciences and Medicines, 7, 34-49.

https://doi.org/10.4236/jbm.2019.75007

Received: March 15, 2019

Accepted: May 14, 2019

Published: May 17, 2019

\begin{abstract}
Recently, health problems related to weight gain and obesity have increased in all age groups, especially adults. Overweight and obese adults are associated with psychological, metabolic and musculoskeletal problems. The aim of this study was to examine foot-loading characteristics during gait of normal-weight; overweight and obese adults aged 25 - 46 years. Methods: This paper outlined tests that were performed on 30 feet of 15 participants. The subjects were gathered in three groups according to their body mass index values, each containing five study participants: five healthy weights (age $35.4 \pm$ $6.3 \mathrm{yrs}, \mathrm{BMI} 21.9 \pm 1.3 \mathrm{~kg} / \mathrm{m}^{2}$ ) matched to five overweight (age $39.2 \pm 6.1 \mathrm{yrs}$, BMI $27.5 \pm 1.34 \mathrm{~kg} / \mathrm{m}^{2}$ ); and five obese adults (age $36.5 \pm 7.8 \mathrm{yrs}$, BMI $34.5 \pm$ $10.3 \mathrm{~kg} / \mathrm{m}^{2}$. The measurements were compared between these groups and the correlation of body mass index with the foot plantar pressure parameters was assessed. Results: The foot pressure measure in the obese group was greater under the metatarsal heads and the heel of the foot compared to the healthy weight group. Moreover, there were rises in pressure beneath the $\mathrm{H}, \mathrm{MF}$, second metatarsal and third metatarsal regions of the foot. It may be considered that in obese individuals, this variation resulted from greater weakness in the ligaments of the foot. As results, the obese group may suffer from discomfort in their feet. The choice of the footwear may depend on the gait and the resulting pain. In addition, they may be less likely to take part in walking or other activities. Therefore, further studies related to these issues, would be advisable. Conclusion: especially, the feet of obese individuals vary from those healthy and overweight adults, because obese subjects' feet are wider. In the obese was established the greatest foot pressure measure increases beneath the heel of the foot and the metatarsal heads.
\end{abstract}

\section{Keywords}

An Advanced Foot Pressure Sensor, Gait, Overweight and Obesity, 
Foot Plantar, Body Mass Index

\section{Introduction}

In the 21st century, the increasing number of overweight and obese adults has become a significant public health concern worldwide, which is associated with both increasing health care cost and disability [1] [2]. In 2016, Excess weight and obese adults are major clinical and public health problems worldwide. The estimated total numbers of more than 1.9 billion adults, 18 years and older, were overweight. Of these over 650 million were obese. 41 million children under the age of five were overweight or obese and over 340 million children and adolescents aged 5 - 19-years-old were overweight or obese in the same period [3]. Healthcare experts and physicians have commonly utilized the body mass index (BMI) scale to define overweight and obesity [4]. BMI $\left(\mathrm{kg} / \mathrm{m}^{2}\right)$ is calculated by dividing weight in kilograms (kg) by the square of the height (length) in meters (m) [5], [3] as described in Equation 1.

A high prevalence of disabling foot pain and perceptions of foot deformities, poor foot health, and the presence of other pain (leg, knee, hip, and lower back pain) have been associated with adults who are overweight or obese [6] [7]. Increased forces and aberrant foot biomechanics may explain the association between obesity and foot pain. In addition, obesity was found to be a significant risk factor for the development of Charcot neuroarthropathy, independent of other risk factors [8]. More recent investigations by [6] have also found that the foot is not immune to the effects of obesity, with a recent systematic review of twenty-five studies involving 93,224 participants concluding that obesity is strongly associated with non-specific foot pain in the general population. A possible explanation for the relationship between obesity and foot pain is that excess bodyweight leads to greater mechanical loading of the foot. Indeed, a link between increased force and pressure under the foot and obesity has been reported [9]. Recently, foot and ankle pathologies such as plantar fasciitis [10] and plantar heel pain [11], [12] have become more prevalent in overweight and obese adults due to increased body weight. A number of research studies have investigated the relationship between plantar pressure and foot pain, finding a clear association between them. Elevated plantar pressures have emerged as a problem for high weight adults during gait. It has been demonstrated that load carriage could adversely affect a number of physiological parameters, such as gait [13] [14]. In addition, obesity increases the ground contact area of the feet, altering the plantar pressure distribution and inducing pressure peaks in certain parts of the foot. However, although the foot is a major part of the skeleton that bears significant loads while standing and walking, only a few studies exist that have investigated plantar forces and peak plantar pressure underneath the foot in obese and control adult subjects [9] [15] [16]. Plantar loading increases in 
obese individuals. Many studies examining this point have been carried out [17] [18] [19] [20]. However, fewer studies have compared the plantar pressures of obese individuals and non-obese individuals [9] [16] [21]. Moreover, we could find no study comparing the plantar pressures of normal weight, overweight and obese individuals as separate groups during the literature review. For this reason, we do not have sufficient information about the difference between the groups in terms of plantar pressures using the insole system, and if the pressure increases in parallel with the level of obesity. From this point, in this paper, the purpose of the study is to assess dynamic foot plantar pressure characteristics in adults, who were normal weight, overweight and obese, during level walking using the insole pressure system, and then to compare those values (findings) with those of a healthy control group.

\section{Methods}

We designed our research to allow the independent variable to be body mass index. The dependent variables were measures of plantar pressure (pressure time integral, peak pressure, pressure contact area and average pressure) over ten regions of the foot namely: (heel (H), midfoot (MF), first metatarsal head (1 MH), second metatarsal head ( $2 \mathrm{MH})$, third metatarsal head ( $3 \mathrm{MH})$, fourth metatarsal head (4 MH), five metatarsal head (5 MH), hallux (1stT), second toe (2ndT), and three to five toes (3rd-5thT) (Figure 1), using F-Scan software (Version 6.70-03, Tekscan, Boston, MA).

\subsection{Test Subjects}

In 2018, the research proposal was accepted by the Research Ethics Committee (proposal number: (H18REA065). All participants signed an informed consent form to participate voluntarily in the study.

Fifteen adult males' participants recruited in this study; the participants were aged between to 29 - 50 years. Adults were excluded from participation in the study if they disclosed a history of orthopaedic problems, any disturbance of balance, musculoskeletal dysfunction or any difficulties in independent locomotion neurological and/or musculoskeletal problems likely to affect their gait. According to the body mass index (BMI) were divided participants into three

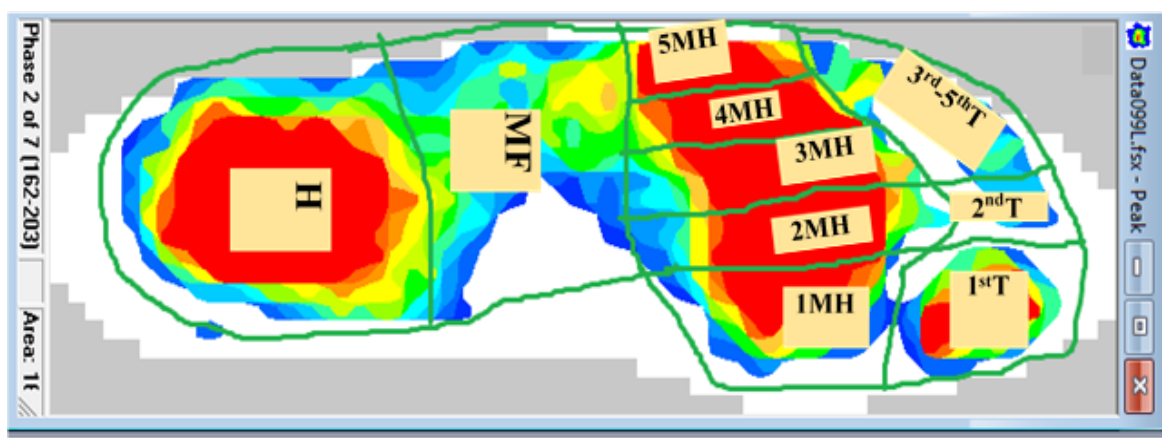

Figure 1. Foot pressure sampling location. 
categories: healthy weight $(\mathrm{BMI}<25)$, overweight $(25<\mathrm{BMI}<30)$, and obese $(\mathrm{BMI}>30)$ as displayed in (Figure 2); which following similar protocols to those used with children and adults, described by [22]; [9] to obtain three groups for comparison.

The participants were divided into three categories namely for a healthy weight, overweight, and obese group. Participant demographics are presented in Table 1 .

\subsection{Instruments}

Plantar pressure measures were recorded using the Tekscan in-shoe pressure system (Tekscan, Boston, MA). This system comprises a wireless transmitter and two sensor cuffs. The in-shoe sensor F-ScanR 3000E standard was utilized. These sensors were approximately $(15 \mathrm{~mm})$ thick and comprised 960 sensing elements. A sampling rate of $100 \mathrm{~Hz}$ was utilized for all trials. All data were collected and processed using the F-Scan Version 6 research software. All walking trials were completed.

\subsection{Foot Pressures}

Protocols for the assessment of plantar pressures in adults previously used in our laboratory were the three-step method wearing the in-sole sensor (Figure 3). The in-sole sensor is becoming increasingly, popular in both research and clinical tools for pressure measurement and force data during dynamic movements, such as evaluating the foot plantar pressure of humans worldwide [23] [24].
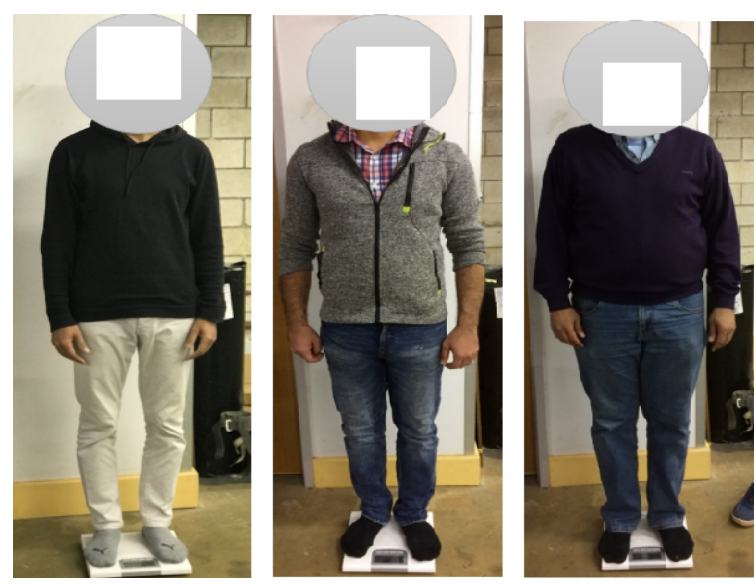

Figure 2. The foot pressure sensor system set-up.

Table 1. Participant demographics.

\begin{tabular}{|c|c|c|c|c|c|c|c|c|c|}
\hline \multirow{2}{*}{ Group } & \multirow{2}{*}{$\mathrm{N}$} & \multicolumn{2}{|c|}{ Age (years) } & \multicolumn{2}{|c|}{ Height (m) } & \multicolumn{2}{|c|}{ Weight (kg) } & \multicolumn{2}{|c|}{ BMI $\left(\mathrm{kg} / \mathrm{m}^{2}\right)$} \\
\hline & & Mean & $\mathrm{SD}$ & Mean & $\mathrm{SD}$ & Mean & $\mathrm{SD}$ & Mean & $\mathrm{SD}$ \\
\hline Healthy & 5 & 35.40 & 6.35 & 1.78 & 0.09 & 69.42 & 7.48 & 21.88 & 1.26 \\
\hline Over-weight & 5 & 36.20 & 4.76 & 1.68 & 0.05 & 76.12 & 6.61 & 26.82 & 1.60 \\
\hline Obese & 5 & 35.4 & 7.4 & 1.7 & 0.1 & 98.7 & 2.9 & 32.9 & 1.7 \\
\hline
\end{tabular}




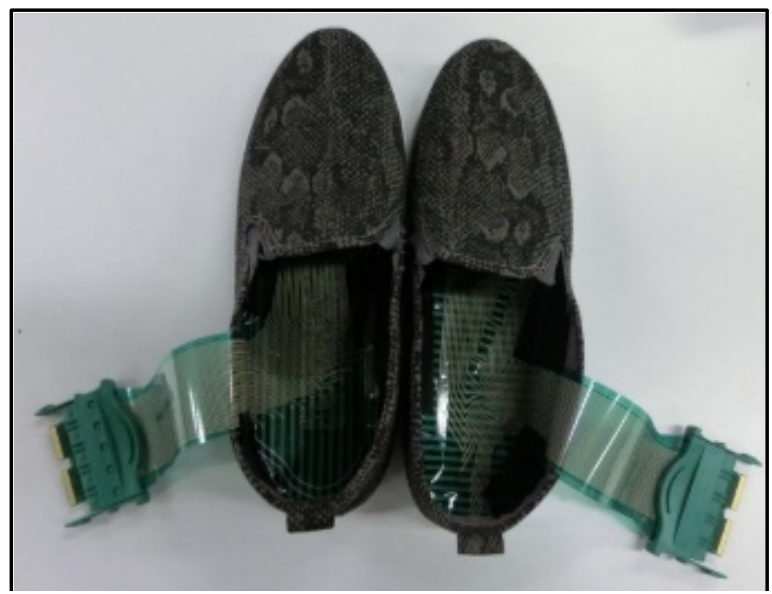

Figure 3. The in-shoe pressure system (Pressure sensor).

All participants were asked to walk along a five-meter walkway with the foot pressure insole system that was attached to the participants' shoes. Participants were instructed to familiarize themselves with the test using the pressure sensing system, thus ensuring that they were comfortable with the procedure. Participants were encouraged to adopt a natural gait pattern and to walk at a self-selected speed. Three trials of the gait were recorded for each participant.

\subsection{Statistical Evaluation of Foot Pressures}

We designed our research to allow the independent variable to be the body mass index. The statistical procedures were conducted using the SPSS software (v.25; SPSS Inc, Chicago, IL, USA). The mean of the three repetitions of each subject was computed and all the statistical procedures were performed with these mean values. All data were analysed using statistical software (SPSS version 25.0). Statistical significance was accepted at the $\mathrm{p}<0.01$ level of confidence. The mean of the three repetitions of each subject was computed and all the statistical procedures were performed with these mean \pm SD values, and presented in the format mean (standard deviation). A one-way Analysis of Variance (ANOVA) was used to test for significant differences in plantar loading measure across the obese, overweight and normal weight groups.

\section{Results}

The three groups (five people in each group) of adult male participants were recruited into the study. Division of these groups was based on participants' body mass and BMI: normal weight, overweight and obese. The participants were aged between 25 and 46 years, and the BMI value obtained for obese adults (32.9 $\left.\mathrm{kg} / \mathrm{m}^{2}\right)$ was significantly higher $(\mathrm{p} \leq 0.001)$ than that of the healthy group $(21.88$ $\mathrm{kg} / \mathrm{m}^{2}$ ). To study the effect of differences in body mass of adults on plantar pressure distribution characteristics (calculating foot force, contact area, contact pressure, peak pressure and pressure time integral in different foot regions during gait) an in-shoe system was used. The characteristics are shown in Table 1. 


\subsection{Force and Contact Area Measurements}

Descriptive data for force $(\mathrm{F}, \mathrm{kg})$ and contact area $\left(\mathrm{CA}, \mathrm{cm}^{2}\right)$ were shown in Appendix Table A1. There was a statistically significant variation ( $\mathrm{P}$-values < 0.001 ) for the force measure (F). The lower differences in mean $F$ measure value were located at the 3rd-5thT and 2ndT between the normal weight and overweight adults for which the value for F was (0.63) and (1.45) respectively. The mean $\mathrm{F}$ measure values were higher for the overweight group compared with the healthy group: which were $(7.13 \mathrm{~kg})$ to $(5.54 \mathrm{~kg})$, respectively.

Statistically significant differences were found between the obese adults group and normal weight adults group in the following regions with mean values for $\mathrm{F}$ measure (P-values $<0.001)$ at the $\mathrm{H}(30.67 \mathrm{~kg}), 1 \mathrm{MH}(14.54 \mathrm{~kg})$ followed by $1 \mathrm{stT}$ and $2 \mathrm{MH}(10.55$ and $10.00 \mathrm{~kg})$ respectively. In contrast, the mean values of the $\mathrm{F}$ variable in the obese group were approximately twice that under the $1 \mathrm{MH}$ $(14.54 \mathrm{~kg}), 1 \mathrm{stT}(10.55 \mathrm{~kg})$ and $2 \mathrm{MH}(10.00 \mathrm{~kg})$ in contrast with the control (healthy) group with values $(7.18,4.62$ and $5.05 \mathrm{~kg}$ ) at the same foot area. A higher correction $(r=0.99)$ was observed between the average values of the $F$ measure and body mass index for these three groups, as shown in (Figure 4(a)).

Illustrative data for $\mathrm{CA}\left(\mathrm{cm}^{2}\right)$ in the adults who were obese, overweight and normal weight is seen in Appendix Table A1. In general, there were statistically significant differences (P-values $<0.001)$ for the CA. The lower differences for the CA measure was located at the 3rd-5thT and 2ndT between the normal weight and overweight adults for which the values for CA were $\left(0.74 \mathrm{~cm}^{2}\right)$ and $\left(1.17 \mathrm{~cm}^{2}\right)$, respectively. The higher CA value was found to be within the overweight group compared with the healthy group.

The overweight group showed greater CA than the normal weight adults of the same age, these differences were located beneath the $\mathrm{H}\left(16.53 \mathrm{~cm}^{2}\right), 1 \mathrm{MH}$ $\left(7.20 \mathrm{~cm}^{2}\right)$, MF $\left(4.90 \mathrm{~cm}^{2}\right)$ followed by $2 \mathrm{MH}\left(4.23 \mathrm{~cm}^{2}\right)$ and $3 \mathrm{MH}\left(4.06 \mathrm{~cm}^{2}\right)$, regions. The obese groups had a higher foot $\mathrm{CA}$ values in comparison with the control group, under the $\mathrm{H}, 1 \mathrm{MH}$ and $\mathrm{MF}$ regions with the value (17.88, 9.41 and $7.88 \mathrm{~cm}^{2}$ ), respectively. Thus, all values were higher within the obese group. Figure 4(b) presents the relationships detected between the CA measurements within these three groups, displaying a strong regression coefficient $(r=0.94)$.

\subsection{Contact Pressure and Pressure-Time Integrals}

A consistent increase of the overall foot loading data for contact pressure (CP, $\mathrm{kPa}$ ) and temporal characteristics of foot loading pressure-time integrals (PTI, $\mathrm{KPa} / \mathrm{s}$ ) for the groups are summarised, as shown in Appendix Table A2. There were significant differences between all three groups in CP and PTI measures which were observed at ( $\mathrm{P}$-values $<0.001)$.

The greater $\mathrm{CP}$ values were under the $2 \mathrm{MH}, 3 \mathrm{MH}, \mathrm{H}, 1$ st T and $1 \mathrm{MH}$ regions in the obese group compared with the normal group. These regions had mean $\mathrm{CP}$ values in the obese group $(118.96,111.27,115.42,103$ and $100.81 \mathrm{KPa})$, respectively. The highest $\mathrm{CP}$ was under the MF in the obese group and the mean 


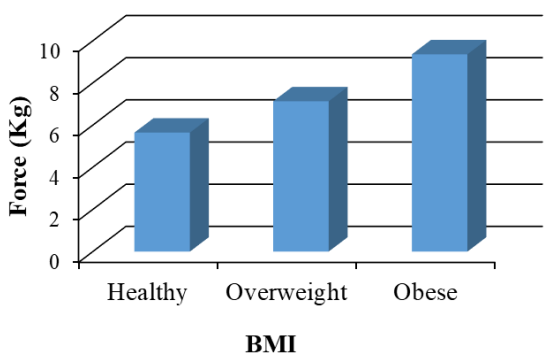

(a)

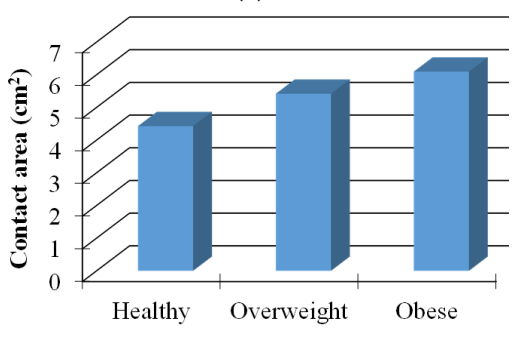

BMI

(b)

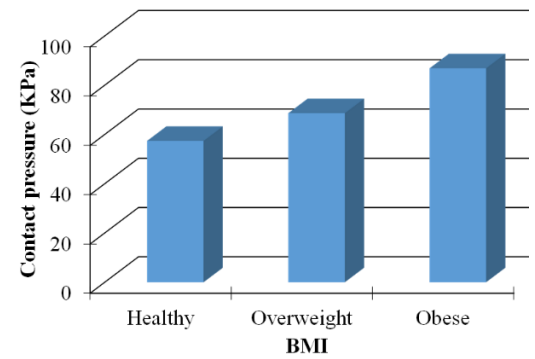

(c)

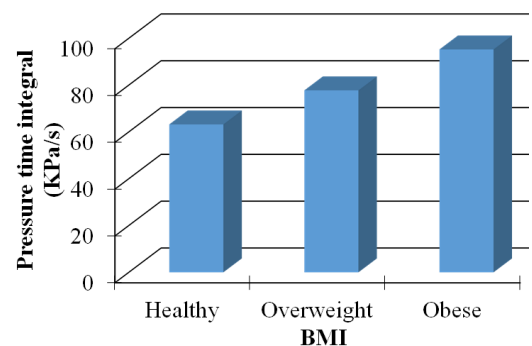

(d)

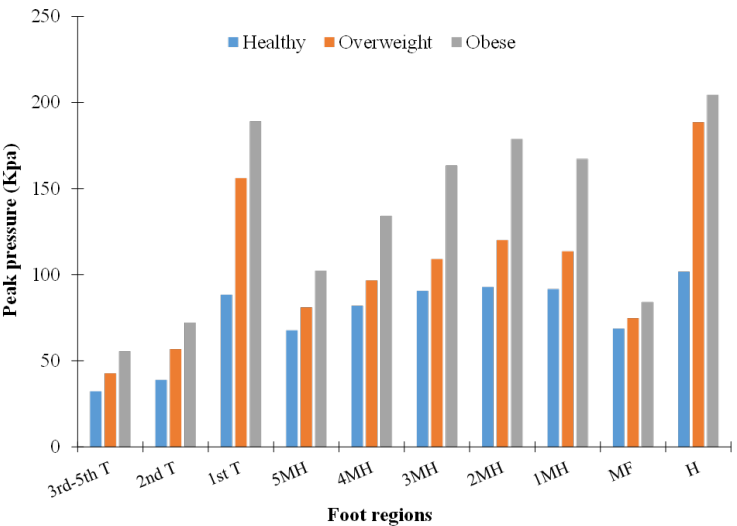

(e)

Figure 4. Results of the preliminary test as mean values for all three groups (from (a), (b), (c), (d), and (e)). 
(85.58 KPa) which was approximately twice the under the same region in the healthy group with a mean of $(42.86 \mathrm{KPa})$. In addition, the obese group presented roughly twice the value under the 1 st $\mathrm{T}$ zone with a mean value (103.84 $\mathrm{KPa})$ compared with the control group (55.38 KPa).

There were slight differences between the overweight and normal weight groups for $\mathrm{CP}$ located at $\mathrm{H}(98.98 \mathrm{KPa}), 2 \mathrm{MH}(84.67 \mathrm{KPa}), 1$ stT $(83.82 \mathrm{KPa})$ and $3 \mathrm{MH}(80.68 \mathrm{KPa})$, in the normal group the $\mathrm{CP}$ values were $(90.20,69.98,55.38$ and $68.14 \mathrm{KPa}$ ) respectively under the same foot area. On the other hand, the lowest $\mathrm{CP}$ value was observed within 3rd-5thT and 2ndT regions with the mean value for overweight ( 37.65 and $42.11 \mathrm{KPa}$ ) and healthy groups (26.32 and 30.89 $\mathrm{KPa})$. The greatest correlation $(\mathrm{r}=99)$ between the $\mathrm{CP}$ measure value and BMI was observed within these three groups as shown in (Figure 4(c)).

Elevated pressure-time integrals (PTI) were attributed to the smallest level of probability (Duncan test) for the PTI for these groups. The normal weight group was (66.93) followed by the overweight (84.50) and the obese group (89.28). The results show higher PTI value underneath the $\mathrm{H}, 1$ stT, $2 \mathrm{MH}$ and $3 \mathrm{MH}$ in the obese group (P-values < 0.001$)$ compared with the control group. The obese group had mean values under the $\mathrm{H}, 1$ stT, $2 \mathrm{MH}$ and $3 \mathrm{MH}$ regions (123.24, $116.63,109.65,100.02 \mathrm{KPa})$, respectively.

The overweight group PTI also was higher compared with the control group beneath the H, $2 \mathrm{MH}$, and 1stT regions; with the mean values of (116.00, 93.64, and $90.81 \mathrm{KPa}$ ) receptively. On the other hand, the lowest region within this PTI measure was absorbed under 3rd-5thT $(58.76,37.04 \mathrm{KPa})$ for both groups (P-values < 0.01) compared with the normal weight $(25.92 \mathrm{KPa})$ group, as shown in Appendix Table A2. It was observed that there was a higher regression coefficient between mean value PTI measures within the three groups, as presented in (Figure 4(d)).

\subsection{Peak Pressure}

The peak plantar pressures (PP) were generally higher in the obese group compared with the other two groups. The highest PP were obtained in the obese group under the $\mathrm{H}(204.38 \mathrm{KPa})$ and 1 stT $(189.00 \mathrm{KPa})$. Descriptive data for the maximum and minimum PP in non-overweight (healthy), overweight and obese groups are represented in (Figure 4(e)) when the obese category was likened to the overweight and healthy categories. The obese group presented the most significant differences for all regions except for the 3rd-5thT and 2ndT, which were slightly dissimilar. The PP value had a maximum variance within the obese group at both regions of $\mathrm{H}(204.38 \mathrm{KPa})$ and the 1 stT $(189.99 \mathrm{KPa})$ approximately double compared with the control group (101.71 and $88.37 \mathrm{KPa}$ ) respectively, within the same area. In addition, the maximum PP value was located below the $\mathrm{H}$ area (204.38). It was found to be greater than both groups (overweight and non-overweight) as displayed in (Figure $4(e)$ ), which shows the comparisons between the non-overweight, overweight and obese groups. 


\section{Discussion}

The experiment was designed to examine the effect of differences in body mass in adults aged between ( 25 and 46 ) years in the three groups (overweight, obese and healthy weight), on plantar pressure distribution characteristics by calculating clinical foot measurements (F, CA, CP, PP and PTI) in ten different foot regions during gait. The findings identified that those who were overweight displayed marked differences in foot loading when compared with adults of healthy weight. Overweight adults generated significantly greater F and CA in the MF and $2 \mathrm{MH}-5 \mathrm{MH}$ regions of the foot; a trend that was similar for the obese adults. Overweight adults also generated increased CP and PTI under the MF and 2nd-5th MH. A similar trend that the obese adults with significant differences also found at the heel in comparison with normal weight adults.Plantar foot pressure parameters such as peak pressure and contact pressure showed statistically significant increases with increasing weight. This was observed with increasing volunteer BMI weight class. The outcomes give important objective knowledge regarding the functional limitations particular to foot mechanics in walking status.

The marked variance in plantar pressures observed as a function of increased adiposity (BMI), which is attention-grabbing to take a position on the structural consequences of repetitive loading on the feet and different components of the lower extremity. The self-reported pain, soreness or discomfort within the feet lower extremity which might be mirrored in the physiological manifestations of loading; as a result of the magnified pressures and forces performing on the system structure of the individual foot. For instance, often heel region pain is distinguished through pain and tenderness on the calcaneal tuberosity within the point of attachment of the plantar fascia [25]. While unknown the particular aetiology of area heel pain, a variety of studies [18] [20] [26] [27] [28] have reported that multiplied weight is an associated issue. The physiological manifestations of loading might be reflected in discomfort in the feet because of the increased pressures and forces acting on the musculoskeletal structure of the human foot. The suggestion that musculoskeletal pain in the feet may reason human to alter their walking strategy in a try to avoid or minimise discomfort [29]. Moreover, [30] stated chronic musculoskeletal pain often is in obese persons. Furthermore, in self-reported losing weight can lead to considerable relief pain. while, others researcher have noticed reduction the feet sensitivity of diabetics, containing skin breakdown and a predisposition to foot ulceration associated with neuropathy in persons at greater static pressures beneath the feet [26] [31]. The major limiting factor in the predisposition of the obese assesses by the ease of walking, as determined via discomfort experienced in the feet, which may be including diabetics who are overweight and obese; to subjects in daily activity such as walking. [32] pointed out that the foot adapts itself to excessive weight bearing by maintaining the medial longitudinal arc. Excessive weight bearing due to increased body weight in subjects with obesity is believed to cause struc- 
tural foot dysfunction, such as the collapse of the longitudinal arc, which especially leads to an increased middle foot contact area [18].

\subsection{Force and Contact Area}

$\mathrm{F}$ values of the total foot were highest for the obese and overweight, and lowest for normal-weight adults, as presented in Figure 4(a). Changes in peak F data were largely eliminated owing to body mass. However, the findings at the Hand forefoot (specifically $2 \mathrm{MH}$ and $3 \mathrm{MH}$ and 1stT) for adults who are obese and overweight demonstrated increased loading at these sites. These results are consistent with previous [18] [20]. These findings have identified elevated levels of loading, in children who are obese at the plantar $\mathrm{H}, \mathrm{MF}$ and $2 \mathrm{MH}-5 \mathrm{MH}$ when compared with non-obese children. The outcomes for F, found by [28], correspond with those of this study. They found that $\mathrm{H}, \mathrm{MF}$ and forefoot had the higher F value. The objective of the study undertaken by [27] was to determine the effects of overweight and obesity on plantar pressures generated by pre-school children during gait. They emphasized that higher stress made the feet of overweight/obese children vulnerable to bony fatigue and soft tissue damage due to higher forces over larger contact areas.

Figure 4(b) showed the remarkable main impact of obesity on dynamic CA. The higher foot CA in overweight and obese adults was compared with their normal-weight counterparts. The higher CA was measured in both groups under the $\mathrm{H}, \mathrm{MF}, 1 \mathrm{MH}, 2 \mathrm{MH}, 3 \mathrm{MH}$ anatomical regions. In this study, the higher $\mathrm{CA}$ within MF was confirmed by previous research [9] [33]. These studies emphasized that the foot pressure distribution parameter power ratio value is greater for the diabetic foot than the normal foot [34]. This power ratio value decreases as the BMI increases because the total contact area increases due to exposure to higher loads, and does not depend on larger feet. Hence this study found significant variations in power ratio value in MF and the plantar ground contact area of overweight subjects compared with healthy subjects while standing because plantar pressure increase begins from the MF in low grade obese subjects (i.e. overweight) due to an increase CA in MF. [28] outcomes for CA correspond with those of this study. They found H, MF and forefoot CA were higher in overweight and obesity compare to healthy children. The study contacted by [28] used children. It assessed plantar pressure in relation to overweight and obesity. They emphasized that increased contact area was not found to be sufficient to compensate for the high forces generated during walking, thus causing higher plantar pressure with increased stress.

Considering that the obese group had the greatest $\mathrm{CA}$ and that the greatest variation between the healthy and obese category the current results disagree with those of [22]. The objective of the study undertaken by [22] was to determine if there are differences in static and dynamic plantar pressure distribution between obese and eutrophic children and, specifically, where the pressure is located on the foot and in what proportion it correlates to body mass. It is accept- 
able to assume that the obese children displayed flattening of the medial longitudinal arch. In contrast, it is not yet clear why this flattening and, consequently, the rise in CA in the MF region occurs.

\subsection{Contact Pressure and Pressure-Time Integrals}

As described in the results section, overweight and obese adults have a higher value of $\mathrm{CP}$ at the $\mathrm{H}, 2 \mathrm{MH}, 3 \mathrm{MH}, 1 \mathrm{MH}, 1$ st T and MF regions. These increased the CP consequences are compatible with [9]. [9] used a pressure distribution platform to asses plantar pressure in obese and healthy adults, when they were both standing and walking states.

They emphasized the reason for subjects to have excessive body weight. In this study, the CP was statistically significantly higher in the $\mathrm{H}, 2 \mathrm{MH}, 3 \mathrm{MH}, 1 \mathrm{MH}$, 1 stT and MF regions. This result was dissimilar to the finding of [35] who found no significant alteration was observed in PP within both metatarsal head area and $\mathrm{H}$ area. [35] determined foot stability according to the results of plantar pressure and spontaneity balance in the normal group and in the obesity, group based on BMI, using a pressure distribution platform. They stressed the reason for participants having a reduction within the spontaneity balance index within the heel region of each of the categories obese and healthy. This is often thought to be a mechanism of compensating for the minimized heel balance within the contact area and foot pressure increasing to make amends for balance. PTI, also referred to as impulse, were found to be statistically higher beneath the $\mathrm{H}, 1 \mathrm{stT}$, 2ndT, $3 \mathrm{MH}, 1 \mathrm{MH}$ and MF. PTI measured value provides information regarding the load distribution over time. The PTI outcomes for [28] correspond with those of this study. [28] found that the MF displayed significantly higher values. [28] was studied to establish the influences of both body conditions overweight and obesity on foot plantar pressures in pre-school children through gait. They found overweight/obese children have higher F, greater CA and higher stress and, in turn, vulnerability to bony fatigue and soft tissue deterioration.

In this study, the PTI was statistically significantly higher in $1 \mathrm{MH}$ to $3 \mathrm{MH}$. This finding is similar to the finding of [36]. [36] investigated the in-shoe pressure differences in Caucasians and Indians. This variable is thought to be important in the pathogenesis of skin lesions [37] [38].

\subsection{Peak Pressure}

As for peak pressure (PP), the obese adults generally displayed greater values than the healthy group during gait however, the $\mathrm{H}, 1$ st $\mathrm{T}$ and metatarsal regions in particular ( $2 \mathrm{MH}, 3 \mathrm{MH}$ and $1 \mathrm{MH}$ ) suffered greater pressure, and the 3 rd-5thT area had the lowest peak pressure, as presented in (Figure 4(e)). The results are in accordance with [9] [18] [21] [22] also found weight to be a significant independent predictor of PP under the $\mathrm{H}, \mathrm{MF}$ and forefoot The aim of the research done by [26] was to find out if excess body weight contributed to increased mean PP foot pressures when foot function, deformity, and structure 
are controlled. The PP outcomes from [28] correspond with those of this study. [28] found that the MF displayed a significantly higher value. In the present study, the PP was statistically significantly higher in the $\mathrm{H}, 1$ st T and metatarsal regions in particular $(2 \mathrm{MH}, 3 \mathrm{MH}$ and $1 \mathrm{MH})$. This finding was similar to that of [20], who found that no significant change was observed in the forefoot and hind-foot peak pressure. The study by study was designed to examine the effects of obesity on dynamic plantar pressure distribution during walking for prepubescent children, using a plantar pressure plate system. They emphasized that higher plantar pressures in obese children will increase loading on the developing foot and may result in foot discomfort and possibly deformity, which may increase the risk of injury. In this study, the highest PP was found under the $\mathrm{H}$. These findings are supported by studies investigating foot function in children [39] [40] and adults [41] [42].

\section{Conclusion}

The current research has explained the differences in the groups in relation to plantar loading. Advanced insole foot pressure sensors have made the demonstration of the effect of overweight on the ankle motion possible. Preliminary tests showed that the technique is practical for clinical study and clinical demonstration. Further testing will be needed to demonstrate the suitability of the techniques for developing an indexing scheme for the study of ankle injury of obese people. Obese and overweight adults showed increases in heel and forefoot regions. In the obese set, the highest foot pressure measure increases were found under the heel of the foot and the metatarsal heads. Observing the changes in plantar pressure with increased BMI, it can be seen that BMI has a marked effect on the structure of the foot. In addition, participants with greater BMI reported suffering discomfort in the feet because of the increased pressure. Plantar heel pain seems to be a common problem. In this area, further study is warranted.

\section{Conflicts of Interest}

The authors declare no conflicts of interest regarding the publication of this paper.

\section{References}

[1] Sheffler, L.R., Bailey, S.N., Gunzler, D. and Chae, J. (2014) Effect of Body Mass Index on Hemiparetic Gait. $P M \& R, 6,908-913$. https://doi.org/10.1016/j.pmrj.2014.03.012

[2] Anandacoomarasamy, A., Caterson, I., Sambrook, P., Fransen, M. and March, L. (2007) The Impact of Obesity on the Musculoskeletal System. Internal Medicine Journal, 37, A35.

[3] World Health Organization (2016) Obesity and Overweight. http://www.who.int/news-room/fact-sheets/detail/obesity-and-overweight

[4] Rossouw, H.A., Grant, C.C. and Viljoen, M. (2012) Overweight and Obesity in Children and Adolescents: The South African problem. South African Journal of 
Science, 108, 1-7. https://doi.org/10.4102/sajs.v108i5/6.907

[5] Jegede, J.A., Adegoke, B.O. and Olagbegi, O.M. (2017) Effects of a Twelve-Week Weight Reduction Exercise Programme on Selected Spatiotemporal Gait Parameters of Obese Individuals. Journal of Obesity, 2017. https://doi.org/10.1155/2017/4193256

[6] Butterworth, P.A., Landorf, K.B., Smith, S.E. and Menz, H.B. (2012) The Association between Body Mass Index and Musculoskeletal Foot Disorders: A Systematic Review. Obesity Reviews, 13, 630-642. https://doi.org/10.1111/j.1467-789X.2012.00996.x

[7] Mickle, K.J., Munro, B.J., Lord, S.R., Menz, H.B. and Steele, J.R. (2011) Gait, Balance and Plantar Pressures in Older People with Toe Deformities. Gait \& Posture, 34, 347-351. https://doi.org/10.1016/j.gaitpost.2011.05.023

[8] Stuck, R.M., Sohn, M.W., Budiman-Mak, E., Lee, T.A. and Weiss, K.B. (2008) Charcot Arthropathy Risk Elevation in the Obese Diabetic Population. The American Journal of Medicine, 121, 1008-1014. https://doi.org/10.1016/j.amjmed.2008.06.038

[9] Hills, A.P., Hennig, E.M., McDonald, M. and Bar-Or, O. (2001) Plantar Pressure Differences between Obese and Non-Obese Adults: A Biomechanical Analysis. International Journal of Obesity, 25, 1674. https://doi.org/10.1038/sj.ijo.0801785

[10] Riddle, D.L., Pulisic, M., Pidcoe, P. and Johnson, R.E. (2003) Risk Factors for Plantar Fasciitis: A Matched Case-Control Study. JBJS, 85, 872-877. https://doi.org/10.2106/00004623-200305000-00015

[11] Irving, D.B., Cook, J.L., Young, M.A. and Menz, H.B. (2007) Obesity and Pronated Foot Type May Increase the Risk of Chronic Plantar Heel Pain: A Matched Case-Control Study. BMC Musculoskeletal Disorders, 8, 41. https://doi.org/10.1186/1471-2474-8-41

[12] Prichasuk, S. (1994) The Heel Pad in Plantar Heel Pain. The Journal of Bone and Joint Surgery: British Volume, 76, 140-142. https://doi.org/10.1302/0301-620X.76B1.8300659

[13] Birrell, S.A. and Haslam, R.A. (2009) The Effect of Military Load Carriage on 3-D Lower Limb Kinematics and Spatiotemporal Parameters. Ergonomics, 52, 1298-1304. https://doi.org/10.1080/00140130903003115

[14] Smith, B., Roan, M. and Lee, M. (2010) The Effect of Evenly Distributed Load Carrying on Lower Body Gait Dynamics for Normal Weight and Overweight Subjects. Gait \& Posture, 32, 176-180. https://doi.org/10.1016/j.gaitpost.2010.04.007

[15] Gravante, G., Russo, G., Pomara, F. and Ridola, C. (2003) Comparison of Ground Reaction Forces between Obese and Control Young Adults during Quiet Standing on a Baropodometric Platform. Clinical Biomechanics, 18, 780-782. https://doi.org/10.1016/S0268-0033(03)00123-2

[16] Birtane, M. and Tuna, H. (2004) The Evaluation of Plantar Pressure Distribution in Obese and Non-Obese Adults. Clinical Biomechanics, 19, 1055-1059. https://doi.org/10.1016/j.clinbiomech.2004.07.008

[17] Deepashini, H., Omar, B., Paungmali, A., Amaramalar, N., Ohnmar, H. and Leonard, J. (2014) An Insight into the Plantar Pressure Distribution of the Foot in Clinical Practice: Narrative Review. Polish Annals of Medicine, 21, 51-56. https://doi.org/10.1016/j.poamed.2014.03.003

[18] Dowling, A.M., Steele, J.R. and Baur, L.A. (2001) Does Obesity Influence Foot Structure and Plantar Pressure Patterns in Prepubescent Children? International Journal of Obesity, 25, 845. https://doi.org/10.1038/sj.ijo.0801598 
[19] Hills, A.P., Hennig, E.M., Byrne, N.M. and Steele, J.R. (2002) The Biomechanics of Adiposity-Structural and Functional Limitations of Obesity and Implications for Movement. Obesity Reviews, 3, 35-43. https://doi.org/10.1046/j.1467-789X.2002.00054.x

[20] Yan, S.H., Zhang, K., Tan, G.Q., Yang, J. and Liu, Z.C. (2013) Effects of Obesity on Dynamic Plantar Pressure Distribution in Chinese Prepubescent Children during Walking. Gait \& Posture, 37, 37-42. https://doi.org/10.1016/j.gaitpost.2012.05.018

[21] Butterworth, P.A., Urquhart, D.M., Landorf, K.B., Wluka, A.E., Cicuttini, F.M. and Menz, H.B. (2015) Foot Posture, Range of Motion and Plantar Pressure Characteristics in Obese and Non-Obese Individuals. Gait \& Posture, 41, 465-469. https://doi.org/10.1016/j.gaitpost.2014.11.010

[22] Filippin, N.T., Barbosa, V.L.P., Sacco, I.C.N. and Lobo da Costa, P.H. (2007) Effects of Obesity on Plantar Pressure Distribution in Children. Brazilian Journal of Physical Therapy, 11, 495-501. https://doi.org/10.1590/S1413-35552007000600012

[23] Waaijman, R. and Bus, S. (2012) The Interdependency of Peak Pressure and Pressure-Time Integral in Pressure Studies on Diabetic Footwear: No Need to Report Both Parameters. Gait \& Posture, 35, 1-5. https://doi.org/10.1016/j.gaitpost.2011.07.006

[24] Chong, A.K., Alrikabi, R. and Milburn, P. (2017) July. Gait COP Trajectory of Left Side Hip-Dislocation and Scoliotic Patient Using Ankle-Foot Orthoses. Ninth International Conference on Digital Image Processing (ICDIP 2017), Vol. 10420, 104204S. International Society for Optics and Photonics. https://doi.org/10.1117/12.2281547

[25] Hill Jr., J.J. and Cutting, P.J. (1989) Heel Pain and Body Weight. Foot \& Ankle, 9, 254-256. https://doi.org/10.1177/107110078900900509

[26] Vela, S.A., Lavery, L.A., Armstrong, D.G. and Anaim, A.A. (1998) The Effect of Increased Weight on Peak Pressures: Implications for Obesity and Diabetic Foot Pathology. The Journal of Foot and Ankle Surgery, 37, 416-420. https://doi.org/10.1016/S1067-2516(98)80051-3

[27] Cousins, S.D., Morrison, S.C. and Drechsler, W.I. (2013) Foot Loading Patterns in Normal Weight, Overweight and Obese Children Aged 7 to 11 Years. Journal of Foot and Ankle Research, 6, 36. https://doi.org/10.1186/1757-1146-6-36

[28] Mickle, K., Steele, J. and Munro, B. (2006) The Feet of Overweight and Obese Young Children: Are They Flat or Fat? Obesity, 4, 1949-1953. https://doi.org/10.1038/oby.2006.227

[29] Messier, S.P., Ettinger, W.H., Doyle, T.E., Morgan, T., James, M.K., O’toole, M.L., Bums, R. and Snow, J.B. (1995) Obesity: Effects on Gait in an Osteoarthritic Population. Medicine \& Science in Sports \& Exercise, 27, S42. https://doi.org/10.1249/00005768-199505001-00240

[30] McGoey, B.V., Deitel, M., Saplys, R.J. and Kliman, M.E. (1990) Effect of Weight Loss on Musculoskeletal Pain in the Morbidly Obese. The Journal of Bone and Joint Surgery: British Volume, 72, 322-323. https://doi.org/10.1302/0301-620X.72B2.2138158

[31] Cavanagh, P.R., Hennig, E.M., Rodgers, M.M. and Sanderson, D.J. (1985) The Measurement of Pressure Distribution on the Plantar Surface of Diabetic Feet. In Biomechanical Measurement in Orthopaedic Practice, Clarendon Press Oxford, 159-166.

[32] Nyska, M., Linge, K., McCabe, C. and Klenerman, L. (1997) The Adaptation of the Foot to Heavy Loads: Plantar Foot Pressures Study. Clinical Biomechanics (Bristol, Avon), 12, S8-S8. https://doi.org/10.1016/S0268-0033(97)88317-9 
[33] Periyasamy, R., Mishra, A., Anand, S. and Ammini, A. (2012) Foot Pressure Distribution Variation in Pre-Obese and Non-Obese Adult Subject While Standing. The Foot, 22, 276-282. https://doi.org/10.1016/j.foot.2012.08.009

[34] Gopalakrishna, K.P., Mothiram, K.P. and Srinivasan, S. (2001) A New Method of Analysis of Standing Foot Pressure Images for Detection of the Plantar Ulcers in Early-Stage Diabetic Neuropathy. Frontiers of Medical and Biological Engineering: The International Journal of the Japan Society of Medical Electronics and Biological Engineering, 11, 31-43. https://doi.org/10.1163/156855701750383178

[35] Yoon, S.W., Park, W.S. and Lee, J.W. (2016) Effects of Body Mass Index on Plantar Pressure and Balance. Journal of Physical Therapy Science, 28, 3095-3098. https://doi.org/10.1589/jpts.29.3095

[36] Putti, A.B., Arnold, G.P. and Abboud, R.J. (2010) Differences in Foot Pressures between Caucasians and Indians. Foot and Ankle Surgery, 16, 195-198. https://doi.org/10.1016/j.fas.2009.11.004

[37] Figueroa, J.L., Fuller, L.C., Abraha, A. and Hay, R.J. (1996) The Prevalence of Skin Disease among School Children in Rural Ethiopia: A Preliminary Assessment of Dermatologic Needs. Pediatric Dermatology, 13, 378-381. https://doi.org/10.1111/j.1525-1470.1996.tb00704.x

[38] Fuller, E. (1996) Computerised Gait Evaluation. In Clinical Biomechanics of the Lower Extremities, Mosby, London, 179-205.

[39] Phethean, J. and Nester, C. (2012) The Influence of Body Weight, Body Mass Index and Gender on Plantar Pressures: Results of a Cross-Sectional Study of Healthy Children's Feet. Gait \& Posture, 36, 287-290. https://doi.org/10.1016/j.gaitpost.2012.03.012

[40] Filippin, N.T., Bacarin, T.D.A. and Lobo da Costa, P.H. (2008) Comparison of Static Footprints and Pedobarography in Obese and Non-Obese Children. Foot \& Ankle International, 29, 1141-1144. https://doi.org/10.3113/FAI.2008.1141

[41] Putti, A.B., Arnold, G.P., Cochrane, L.A. and Abboud, R.J. (2008) Normal Pressure Values and Repeatability of the Emed (R) ST4 System. Gait Posture, 27, 501-505. https://doi.org/10.1016/j.gaitpost.2007.06.009

[42] Scott, G., Menz, H.B. and Newcombe, L. (2007) Age-Related Differences in Foot Structure and Function. Gait \& Posture, 26, 68-75.37. https://doi.org/10.1016/j.gaitpost.2006.07.009 


\section{Appendix}

Table A1. Summary of the dynamic force $(\mathrm{kg})$ and contact area $\left(\mathrm{cm}^{2}\right)$ data for the normal weight $(\mathrm{n}=5)$, overweight $(\mathrm{n}=5)$ and obese $(n=5)$ [Mean $(S D)$ of three trials].

\begin{tabular}{|c|c|c|c|c|c|c|c|c|c|c|c|c|}
\hline \multirow{3}{*}{$\begin{array}{c}\text { Foot } \\
\text { regions }\end{array}$} & \multicolumn{6}{|c|}{ Force $(\mathrm{kg})$} & \multicolumn{6}{|c|}{ Contact area $\left(\mathrm{cm}^{2}\right)$} \\
\hline & \multicolumn{2}{|c|}{ Healthy } & \multicolumn{2}{|c|}{ Overweight } & \multicolumn{2}{|c|}{ Obese } & \multicolumn{2}{|c|}{ Healthy } & \multicolumn{2}{|c|}{ Overweight } & \multicolumn{2}{|c|}{ Obese } \\
\hline & Mean & $\mathrm{SD}$ & Mean & $\mathrm{SD}$ & Mean & SD & Mean & $\mathrm{SD}$ & Mean & $\mathrm{SD}$ & Mean & SD \\
\hline 3 rd-5thT & 0.63 & 0.69 & 1.45 & 1.32 & 1.53 & 1.88 & 0.74 & 0.66 & 1.17 & 1.01 & 1.37 & 1.15 \\
\hline 2ndT & 0.77 & 0.56 & 1.10 & 1.14 & 1.26 & 1.11 & 0.81 & 0.55 & 0.83 & 0.70 & 0.84 & 0.45 \\
\hline $1 \mathrm{st} \mathrm{T}$ & 4.62 & 3.73 & 5.96 & 5.51 & 10.55 & 8.33 & 3.21 & 1.43 & 2.99 & 1.33 & 4.77 & 1.82 \\
\hline $5 \mathrm{MH}$ & 2.66 & 1.62 & 3.17 & 1.85 & 3.85 & 3.01 & 2.57 & 1.44 & 2.87 & 1.37 & 3.16 & 1.38 \\
\hline $4 \mathrm{MH}$ & 3.55 & 1.86 & 4.04 & 1.52 & 6.49 & 3.69 & 3.08 & 1.50 & 3.42 & 1.07 & 4.57 & 1.31 \\
\hline $3 \mathrm{MH}$ & 4.39 & 2.09 & 5.73 & 2.95 & 8.30 & 2.37 & 3.56 & 1.63 & 4.06 & 0.91 & 5.27 & 1.23 \\
\hline $2 \mathrm{MH}$ & 5.05 & 2.10 & 7.05 & 3.91 & 10.00 & 2.58 & 3.94 & 1.64 & 4.23 & 0.93 & 5.81 & 1.37 \\
\hline $1 \mathrm{MH}$ & 7.18 & 3.58 & 10.47 & 4.09 & 14.54 & 3.59 & 6.15 & 2.80 & 7.20 & 1.78 & 9.41 & 2.54 \\
\hline $\mathrm{MF}$ & 3.11 & 4.12 & 4.68 & 4.15 & 6.39 & 4.65 & 3.68 & 3.14 & 4.90 & 5.64 & 7.88 & 6.49 \\
\hline $\mathrm{H}$ & 23.47 & 7.12 & 27.64 & 9.5 & 30.67 & 13.43 & 15.55 & 4.47 & 16.53 & 5.72 & 17.88 & 6.21 \\
\hline
\end{tabular}

Table A2. Summary of the contact pressure $(\mathrm{kPa})$ and pressure-time integral $(\mathrm{kPa} / \mathrm{s})$ data for the normal weight $(\mathrm{n}=5)$, overweight $(n=5)$ and obese $(n=5)$ [Mean (SD) of three trials].

\begin{tabular}{|c|c|c|c|c|c|c|c|c|c|c|c|c|}
\hline \multirow{3}{*}{ Foot Region } & \multicolumn{6}{|c|}{ Contact pressure $(\mathrm{kPa})$} & \multicolumn{6}{|c|}{ Pressure-time integrals $(\mathrm{KPa} / \mathrm{s})$} \\
\hline & \multicolumn{2}{|c|}{ Healthy } & \multicolumn{2}{|c|}{ Overweight } & \multicolumn{2}{|c|}{ Obese } & \multicolumn{2}{|c|}{ Healthy } & \multicolumn{2}{|c|}{ Overweight } & \multicolumn{2}{|c|}{ Obese } \\
\hline & Mean & SD & Mean & SD & Mean & SD & Mean & SD & Mean & SD & Mean & SD \\
\hline 3rd-5thT & 26.32 & 19.49 & 37.65 & 38.75 & 34.01 & 28.50 & 28.34 & 25.92 & 37.04 & 31.42 & 58.76 & 84.96 \\
\hline 2ndT & 30.89 & 22.32 & 42.11 & 34.22 & 52.67 & 50.41 & 34.58 & 30.20 & 44.62 & 40.97 & 82.59 & 119.65 \\
\hline 1 st $\mathrm{T}$ & 55.38 & 30.32 & 83.82 & 69.30 & 103.84 & 86.92 & 57.31 & 43.96 & 90.81 & 96.60 & 116.63 & 157.38 \\
\hline $5 \mathrm{MH}$ & 52.80 & 22.86 & 62.97 & 34.58 & 75.91 & 43.70 & 61.14 & 35.33 & 65.97 & 28.04 & 74.10 & 38.73 \\
\hline $4 \mathrm{MH}$ & 63.86 & 22.76 & 73.77 & 32.13 & 97.32 & 45.81 & 70.77 & 33.60 & 78.33 & 37.72 & 96.25 & 42.16 \\
\hline $3 \mathrm{MH}$ & 68.14 & 21.52 & 80.68 & 27.11 & 111.27 & 34.20 & 77.95 & 30.41 & 83.80 & 41.38 & 100.02 & 41.21 \\
\hline $2 \mathrm{MH}$ & 69.98 & 20.54 & 84.67 & 25.44 & 118.96 & 31.34 & 84.57 & 37.32 & 93.64 & 50.27 & 109.65 & 53.41 \\
\hline $1 \mathrm{MH}$ & 61.53 & 19.52 & 70.90 & 26.04 & 100.81 & 27.33 & 70.82 & 38.14 & 86.56 & 44.56 & 101.12 & 40.76 \\
\hline MF & 42.86 & 26.44 & 50.93 & 15.20 & 85.58 & 38.21 & 35.21 & 44.65 & 49.94 & 15.80 & 58.21 & 44.71 \\
\hline $\mathrm{H}$ & 90.20 & 24.75 & 98.98 & 25.95 & 115.42 & 61.73 & 93.54 & 28.91 & 116.00 & 73.96 & 123.24 & 68.36 \\
\hline
\end{tabular}

